\title{
Aprendizagem significativa: concepções na formação inicial de professores de Ciências
}

\author{
Meaningful learning: conceptions in the initial training of science \\ teachers
}

\author{
Jennifer Alejandra Suárez Silva (jsuarezs@edicacionbogota.edu.com) \\ Programa de Pós-Graduação em Educação em Ciências: Química da Vida e Saúde (PPGECQV) \\ Universidade Federal de Santa Maria (UFSM) \\ Mara Elisa Fortes Braibante (maraefb@gmail.com) \\ Programa de Pós-Graduação em Educação em Ciências: Química da Vida e Saúde (PPGECQV) \\ Universidade Federal de Santa Maria (UFSM)
}

\begin{abstract}
Resumo:
O presente trabalho apresenta os resultados de uma investigação qualitativa que visa analisar as concepções de um grupo de professores em formação inicial, sobre o processo de ensino-aprendizagem. Identificando se os professores em formação inicial: consideram a aprendizagem significativa como um objetivo da educação; conhecem sua teoria e suas condições para alcança-la na sala de aula e o modelo epistemológico adotado. Além disso, apresenta-se um referencial teórico que aborda a aprendizagem significativa e suas contribuições na formação de professores. Nos resultados obtidos destaca-se a importância da formação inicial de professores e o fortalecimento das concepções pedagógicas e didáticas para conseguir mudanças nos processos educativos.
\end{abstract}

Palavras chave: Aprendizagem significativa; formação inicial de professores.

\begin{abstract}
:
This paper presents the results of a qualitative research to analyze the conceptions of a teachers group in initial training about teaching-learning process. Identifying whether teachers in initial training: they consider meaningful learning as a goal of education, they know their theory and their conditions to reach it in the classroom and the epistemological model adopted. In addition, it presents a theoretical framework that approaches the meaningful learning and its contributions to the training of teachers. The results highlight the importance of initial teacher training and the strengthening of pedagogical and didactic concepts to achieve changes in the educational processes.
\end{abstract}

Keywords: Meaningful learning; Initial teacher training.

\section{INTRODUÇÃ̃O}


Na sala de aula, muitos professores ainda ensinam os conteúdos da mesma forma como eles aprenderam, o que faz com que os métodos de ensino não se diferenciem dos que conhecíamos como estudantes anos atrás (RODRIGUEZ; CABALLERO; MOREIRA, 2011) posto que não acrescentam novas metodologias. Gil, P. (1991) nomeia este fato como "pedagogia do senso comum", sendo uma pedagogia que parte das coisas que o professor já sabe como ideias, atitudes e comportamentos sobre o processo de ensino que desenvolveram dentro do período que foram estudantes, o que impede uma atividade docente inovadora e criativa. Por esta razão, para que ocorra a aprendizagem significativa é preciso que haja mudanças na postura dos docentes relacionadas a suas metodologias de ensino, optando por alternativas didáticas que favoreçam à construção da aprendizagem de forma significativa.

No entanto, os professores de ciências em formação inicial sabem o que é a aprendizagem significativa e as condições para consegui-la na sala de aula? Dado que, a aprendizagem significativa é um objetivo a ser alcançado com os estudantes. Visto que é proposto nos Parâmetros Curriculares Nacionais para o Ensino Médio (PCNEM), desde o ano de 1998 no ensino de ciências, ao mencionar que "o processo de ensino e aprendizagem na área de Ciências Naturais pode ser desenvolvido dentro de contextos social e culturalmente relevantes, que potencializam a aprendizagem significativa" (BRASIL; 1998, p.28). Mais tarde, em 2002, conforme os PCNEM+:

\begin{abstract}
A proposta apresentada para o ensino de Química nos PCNEM se contrapõe à velha ênfase na memorização de informações, nomes, fórmulas e conhecimentos como fragmentos desligados da realidade dos alunos. Ao contrário disso, pretende que o aluno reconheça e compreenda, de forma integrada e significativa, as transformações químicas que ocorrem nos processos naturais e tecnológicos em diferentes contextos, encontrados na atmosfera, hidrosfera, litosfera e biosfera, e suas relações com os sistemas produtivo, industrial e agrícola (BRASIL, 2002, p. 87).
\end{abstract}

E finalmente, as Orientações Curriculares para o Ensino Médio, de 2006, enfatizam que: "a simples transmissão de informações não é suficiente para que os alunos elaborem suas ideias de forma significativa" (BRASIL, 2006, p.123).

Para responder a pergunta, neste trabalho, faz-se uma breve descrição da teoria da aprendizagem significativa proposta por Ausubel e seu papel na formação de professores e, em um segundo momento, analisam-se as concepções de um grupo de 
professores em formação inicial sobre o processo de ensino - aprendizagem. Por último, apresentam-se algumas considerações finais e sugestões sobre: o processo de ensinoaprendizagem e a formação inicial de professores.

\section{APRENDIZAGEM SIGNIFICATIVA}

A aprendizagem de forma significativa pelos estudantes, deve ser um objetivo a ser alcançado pelos professores dentro do processo de ensino - aprendizagem, sendo uma alternativa para mudar metodologias tradicionais para metodologias construtivistas, com a finalidade de que o conhecimento deixe de ser mecânico e passe a ter um significado para o estudante. Mas, o que é a aprendizagem significativa? É uma teoria proposta por David P. Ausubel em 1963, que vem sendo complementada por outros autores, cada um agregando sua visão, passando da visão inicial clássica até uma visão crítica desta teoria, descrita por Moreira (2005), conforme Quadro 1.

Quadro 1 - Aprendizagem significativa: da visão clássica à visão crítica (continua)

\begin{tabular}{|c|c|c|c|}
\hline 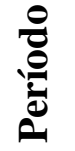 & Autor & Visão & Definição de aprendizagem significativa \\
\hline ชె & $\begin{array}{l}\text { David } \\
\text { Ausubel }\end{array}$ & Clássica & $\begin{array}{l}\text { Interação cognitiva não-arbitrária e não-literal entre o } \\
\text { novo conhecimento, potencialmente significativo, e } \\
\text { algum conhecimento prévio, especificamente } \\
\text { relevante, o chamado subsunçor, existente na } \\
\text { estrutura cognitiva do aprendiz. }\end{array}$ \\
\hline$\stackrel{\text { § }}{\curvearrowright}$ & $\begin{array}{l}\text { Joseph } \\
\text { Novak }\end{array}$ & Humanista & $\begin{array}{l}\text { Conotação humanista que subjaz à integração } \\
\text { construtiva, positiva, entre pensamentos, sentimentos } \\
\text { e ações que conduz ao engrandecimento humano. }\end{array}$ \\
\hline$\stackrel{1}{\infty}$ & Gowin & $\begin{array}{l}\text { Interacionista } \\
\text { social }\end{array}$ & $\begin{array}{l}\text { Abordagem triádica (aluno - professor - Materiais } \\
\text { educativos do currículo), na qual o processo ensino- } \\
\text { aprendizagem é uma negociação de significados cujo } \\
\text { objetivo é compartilhar significados a respeito dos } \\
\text { materiais educativos do currículo. }\end{array}$ \\
\hline
\end{tabular}




\begin{tabular}{|c|c|c|c|}
\hline 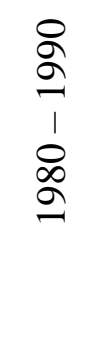 & $\begin{array}{l}\text { Johnson- } \\
\text { Laird }\end{array}$ & $\begin{array}{l}\text { Cognitiva } \\
\text { contemporânea }\end{array}$ & $\begin{array}{l}\text { Construção de modelos mentais a partir de } \\
\text { conhecimentos que o indivíduo já tem em sua } \\
\text { estrutura cognitiva e daquilo que ele percebe de uma } \\
\text { nova situação (novo conhecimento), seja por } \\
\text { percepção direta, descrição ou representação dessa } \\
\text { situação. }\end{array}$ \\
\hline
\end{tabular}

Quadro 1 - Aprendizagem significativa: da visão clássica à visão crítica.

(conclusão)

\begin{tabular}{|c|c|c|c|}
\hline$\frac{0}{\frac{0}{0}}$ & Autor & Visão & Definição de aprendizagem significativa \\
\hline \multirow{3}{*}{ 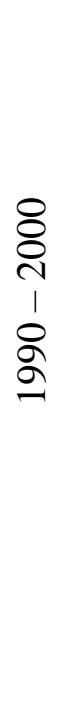 } & Vergnaud & $\begin{array}{l}\text { Complexidade } \\
\text { e } \\
\text { progressividade }\end{array}$ & $\begin{array}{l}\text { Construção de campos conceituais através da interação } \\
\text { entre situações-problema (novos conhecimentos) e os } \\
\text { conceitos em construção (subsunçores). }\end{array}$ \\
\hline & Maturana & Autopoiética & $\begin{array}{l}\text { Interações perturbadoras entre a perturbação (novo } \\
\text { conhecimento) e as explicações reformuladas pela } \\
\text { experiência (subsunçores), que modificam a estrutura } \\
\text { dos conhecimentos prévios sem alterar sua } \\
\text { organização. }\end{array}$ \\
\hline & $\begin{array}{l}\text { Araújo e } \\
\text { Veit }\end{array}$ & Computacional & $\begin{array}{l}\text { Construção de representações mentais, que são } \\
\text { representações internas com um certo grau de } \\
\text { estabilidade, que podem modificar-se na medida em } \\
\text { que incorporam novas informações. }\end{array}$ \\
\hline$\underset{丶}{8}$ & Moreira & Critica & $\begin{array}{l}\text { Integração que o sujeito faz entre os conhecimentos } \\
\text { significativos e a sociedade de forma crítica, } \\
\text { subversiva e antropológica. }\end{array}$ \\
\hline
\end{tabular}

Fonte: Adaptação de MOREIRA (2005).

Esta teoria se fundamenta na construção de um novo conhecimento, a partir da interação não-arbitrária e não-literal com os conhecimentos prévios. Isso quer dizer que o estudante precisa do conhecimento prévio relevante dentro de sua estrutura cognitiva 
para dar-lhe significado, ao contrário, não poderá obter uma aprendizagem significativa. (MOREIRA et al. 2008). Para exemplificar, pode-se citar a aprendizagem da bioquímica orgânica. Se o aprendiz tiver conhecimento de conceitos como: funções orgânicas (aldeídos, cetonas, aminas, etc.) em sua estrutura cognitiva, quando um novo conceito for apresentado, como carboidratos ou proteínas, este irá interagir com o conhecimento já existente. No entanto, não são necessários só os conhecimentos prévios para construir a aprendizagem significativa, precisa-se de outras duas condições para sua construção: um material potencialmente significativo e a predisposição para aprender por parte do estudante.

Os conhecimentos prévios são subsunçores que servem como ancoradouros para o novo conhecimento (Moreira et al. 2008) e são definidos por Castillo, Ramirez e Gonzalez (2013, p.16) como:

Construções pessoais, muitas delas guiadas pela percepção e a experiência dos estudantes em suas vidas diárias, algumas vezes, são fortes e consequentemente difíceis de modificar. Especialmente aquelas que estão ligadas a situações da vida cotidiana em que essas ideias são perfeitamente adequadas e formam parte de um modelo mental explicativo. (CASTILLO; RAMIREZ; GONZALES. 2013, p.16).

Estes conhecimentos podem tanto favorecer o processo de ensino-aprendizagem quanto ser um obstáculo para o mesmo, motivo pelo qual é aconselhável que sejam identificados antes da aplicação de quaisquer atividades, dado que, na educação cientifica, como a química, não se pode pensar que os estudantes partem de um conhecimento zero (GIL, 1983), considerando que os mesmos aprendem não só na escola, mas também na vida diária, através de diferentes fontes de informação e de suas próprias experiências.

Além disso, os conhecimentos prévios são importantes para a elaboração e aplicação de materiais potencialmente significativos, em razão de iniciar ou continuar o processo de ensino fazendo uso dos subsunçores presentes na estrutura do aprendiz, como é mencionado por Ausubel (1978, p.78 apud MOREIRA, 2009, p.7). "Se tivesse que reduzir toda a psicologia educacional a um só princípio, diria o seguinte: o fator isolado mais importante que influencia a aprendizagem é aquilo que o aprendiz já sabe. Averigue isso e ensine-o de acordo". Desse modo, o material potencialmente 
significativo será lógico, coerente e relacionável com a estrutura cognitiva de quem aprende e com os conteúdos a ensinar, de maneira não-arbitrária e não-literal, uma das condições para a ocorrência da aprendizagem significativa (MOREIRA, 2011; RODRIGUEZ et al, 2010).

Porém, ter os subsunçores necessários e o material potencialmente significativo, não assegura a construção da aprendizagem significativa, se o estudante não manifesta uma disposição para relacioná-los (MOREIRA, 2011). Por isso, outra condição necessária é a atitude potencialmente significativa ou predisposição para aprender por parte do aprendiz (RODRIGUEZ et al, 2010), do contrário, a aprendizagem será mecânica (ou automática) por ser arbitrária ou literal (MOREIRA, 2011)

\section{APRENDIZAGEM SIGNIFICATIVA E FORMAÇÃO INICIAL DE PROFESSORES}

A palavra formação é definida por dicionários da língua portuguesa como uma "ação" ou "ato" que expressa o processo de: produzir, elaborar, desenvolver, compor, ordenar, ensinar, disciplinar e/ou orientar. No contexto acadêmico ou profissional, a formação consiste em aumentar e adequar o conhecimento e as habilidades (CONCEITO, 2011). A formação de professores é considerada uma ação continuada, ou seja, um processo de constante desenvolvimento que acontece por toda a vida profissional (SERRA, 2012).

A formação de professores, principalmente a formação de professores para o ensino médio, em cursos regulares e específicos como as ciências, surgiu no início do século XX (OLIVEIRA et al. 2012). No entanto, até hoje é objeto de críticas por não atender suficientemente as necessidades da sociedade brasileira e por não acompanhar as modificações devido às mudanças da sociedade entre as quais podemos citar: políticas, sociais, culturais e econômicas. Mudando conjuntamente as exigências da formação dos professores (HYPOLITTO, 2009; OLIVEIRA et al. 2012).

Uma das críticas ressaltada por Hypólito, D. (2009, p.93) é que "o aluno sai do curso de formação de professores apenas com um diploma. Não está preparado para ensinar, não domina o conteúdo, não conhece metodologias eficazes, falta-lhe estimulo para enfrentar uma classe agitada, indisciplinada, apática e passiva". Sendo portanto, 
importante perguntar quais são os conhecimentos ou saberes que o professor deve desenvolver na formação inicial para que seu trabalho em sala de aula seja considerado de qualidade e favoreça a aprendizagem significativa? Uma das teorias para responder a esta pergunta é proposta por Gil, P. (1991) ao mencionar que o professor deveria saber:

1. A disciplina que vai ensinar: conhecer os conteúdos teóricos e práticos (metodologias) possibilitando a articulação com outras disciplinas, a elaboração de metodologias inovadoras e a contextualização dos conteúdos com o cotidiano dos estudantes, permitindo uma visão atual da ciência, promovendo o interesse por aprender e evitando o desenvolvimento de erros conceituais ou epistemológicos nos estudantes.

2. Conhecimentos teóricos sobre o processo de ensino-aprendizagem das ciências: conhecimentos pedagógicos, psicológicos e sociológicos que permitam que o professor compreenda e favoreça a aprendizagem. Uma aprendizagem significativa onde o estudante seja participante na construção de seu conhecimento e o professor reconheça a importância das atitudes e as preconcepções dos estudantes, além da importância das interações sociais na construção do conhecimento científico.

3. Realizar críticas sobre o processo de ensino.

4. Elaborar atividades de aprendizagem: saber elaborar atividades que gerem o interesse dos estudantes por aprender, levando em conta os pré-requisitos para iniciar os estudos em um conteúdo, as ideias, visões do mundo e atitudes que os estudantes possuem.

5. Orientar as atividades dos alunos.

6. Avaliar o processo de ensino-aprendizagem: utilizar a avaliação como instrumento de aprendizagem e introduzir formas de avaliação de sua tarefa como professor para melhorar os processos de ensino.

7. Desenvolver atividades de investigação e inovação.

Além dos conhecimentos mencionados por Gil considera-se importante na formação inicial de professores que se fortaleça os conhecimentos metodológicos práticos ou didáticos que favoreçam a aprendizagem significativa em sala de aula. Posto que, alguns educadores consideram suficiente somente seleccionar conteudos e 
encontrar uma técnica para desenvolver na sala de aula, sem levar em consideração a metodologia e as condições para conseguir uma aprendizagem significativa, devido ao fato de não conhecer esta teoria.

É necessário que a elaboração das metodologias seja organizada não exatamente da mesma maneira que os conteúdos são organizados dentro dos livros didáticos, porque os livros não levam em conta as estruturas mentais dos estudantes, suas ideias, crenças, necessidades e interesses (MENDEZ, 1993).

Por isso, Rodriguez, Caballero e Moreira, (2011) propõem como tarefas que os professores determinem a estrutura conceitual do que vão ensinar e identifiquem os conceitos subsunçores na estrutura cognitiva do estudante, antes de iniciarem qualquer metodologia de ensino. Tais tarefas têm o objetivo de organizar os conteúdos, implementar a metodologia elaborada e por último avaliar os resultados obtidos com a aplicação, conforme Figura 1.

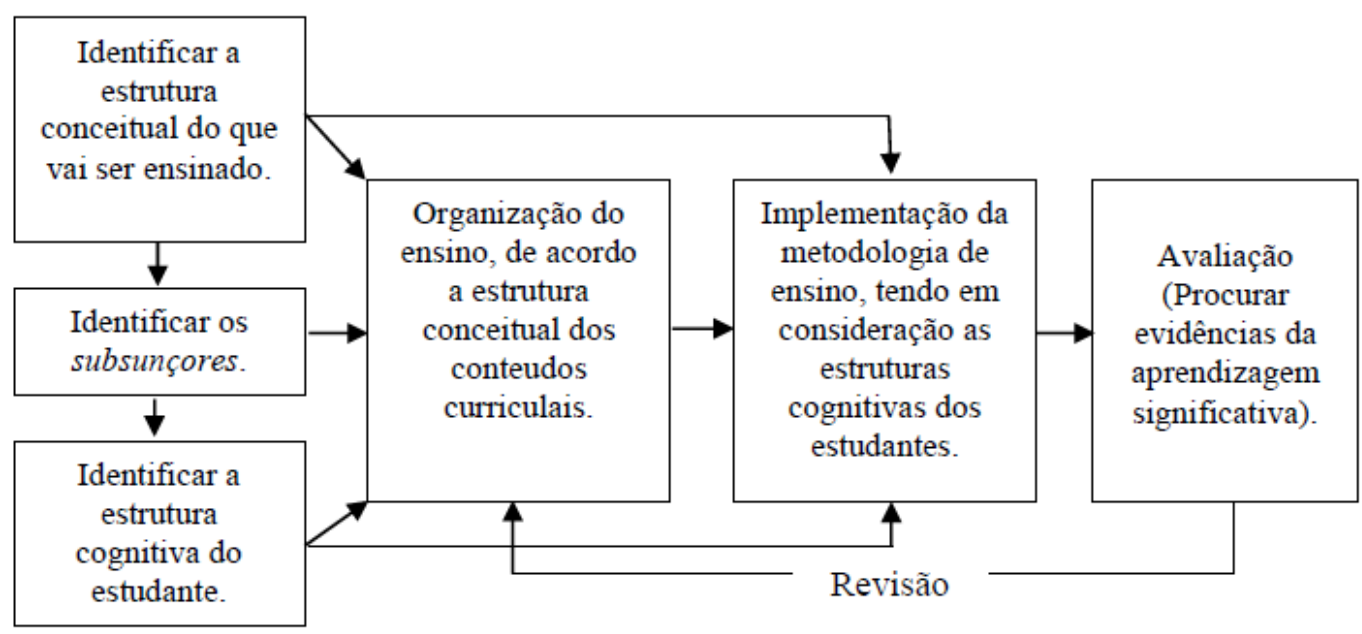

Figura 1 - Modelo para organizar, implementar e avaliar o processo de ensino para conseguir uma aprendizagem significativa. (Adaptação de RODRIGUEZ, CABALLERO e MOREIRA (2011, p. 78)).

Por tudo isto, recomenda-se aos professores em formação inicial e aos professores em exercício, princípios para o desenvolvimento da aprendizagem significativa, propostos por Diaz e Hernandez (2002, apud RODRIGUEZ, CABALLERO e MOREIRA, 2011, p.73), que são: 
1. A Aprendizagem é facilitada quando os conteúdos são apresentados aos estudantes de forma organizada, com uma sequência lógica e psicológica apropriada.

2. Os conteúdos escolares devem ser apresentados em forma de sistemas conceituais (esquemas de conhecimentos) organizados, inter-relacionados e com uma hierarquia.

3. A utilização dos conhecimentos e experiências prévias que o aprendiz possui na estrutura cognitiva, facilita os processos da aprendizagem significativa dos novos materiais de estudo.

4. Estabelecer "pontes cognitivas" que podem orientar os estudantes a organizar e interpretar de forma significativa o conhecimento.

5. Os conteúdos aprendidos de forma significativa por recepção ou descobrimento são mais estáveis e menos vulneráveis ao esquecimento.

6. Estimular a motivação e participação ativa do estudante para aumentar o significado potencial dos materiais acadêmicos.

\section{METODOLOGIA}

A metodologia de investigação utilizada dentro desta pesquisa é considerada como uma metodologia de caráter qualitativo. Esta metodologia é amplamente empregada nas pesquisas educacionais devido ao fato de ser um processo empírico que se constrói socialmente, preocupar-se mais com a compreensão do fenômeno social, ser participativa e o pesquisador ter a oportunidade de estar imerso no fenômeno de interesse (FIRESTONE, 1987, p. 16 - 17 apud Moreira, 2003).

A coleta de dados foi realizada com um grupo de 6 professores de química em formação inicial (PFI), a pequena amostra utilizada se justifica no número de estudantes que são participantes do Programa Institucional de Bolsa de Iniciação à Docência (PIBID). Os quais com sua participação no PIBID fortalecem suas concepções pedagógicas e didática, por meio, da construção de metodologias de ensino na área de ciências, como: oficinas temáticas, experimentação investigativa, temas geradores, três momentos pedagógicos, jogos didáticos, estudos de caso, entre outros. 
Os dados foram obtidos através de um questionário contendo 10 questões que tinham como objetivo identificar o perfil dos PFI, sua escolha pela profissão docente, a predileção pela docência em ciências, se consideram a aprendizagem significativa como um objetivo da educação, se conhecem esta teoria e suas condições para consegui-la na sala de aula e o modelo epistemológico adotado.

As respostas dos PFI, foram analisadas por meio da Análise Textual Discursiva (ATD) que é "uma abordagem de análise de dados que transita entre duas formas consagradas de análise na pesquisa qualitativa que são a análise de conteúdo e a análise de discurso" (MORAES, GALIAZZI, 2006, p.118). A ATD foi elaborada a partir da construção de categorias a priori e emergentes. As categorias a priori foram construídas para os temas da análise conhecidas antecipadamente considerando os objetivos da pesquisa, no caso das categorias emergentes, foram feitas utilizando as informações obtidas pelas respostas do questionário.

A construção das categorias iniciou-se com a separação dos textos ou corpus em unidades de significado, o que implicou no recorte das respostas em fragmentos de proposições que possuíam significado para a análise. Em seguida, agrupou-se as unidades de significado semelhantes nas categorias estabelecidas. Por último, elaborouse os metatextos analíticos com a discussão dos resultados.

Considerando o exposto, os tópicos para sua análise estão apresentadas no Quadro 2.

Quadro 2 - Tópicos da pesquisa.

Fonte: autores

\begin{tabular}{|c|l|}
\hline N. & \multicolumn{1}{|c|}{ Tópicos da pesquisa } \\
\hline 1 & Escolha pela profissão docente \\
\hline 2 & Predileção pela docência em ciências \\
\hline 3 & Objetivo da educação \\
\hline 4 & Modelo epistemológico \\
\hline 5 & Critérios para o planejamento da aula \\
\hline 6 & Atividades didáticas \\
\hline 7 & $\begin{array}{l}\text { Critérios para escolher as atividades de sala de } \\
\text { aula }\end{array}$ \\
\hline
\end{tabular}

\section{RESULTADO E DISCUSSÃO}


Apresentamos a seguir, os metatextos analíticos da pesquisa para cada tópico:

1. Escolha pela profissão docente: A escolha profissional e a inserção no mundo do trabalho, segundo Gatti et. al. (2009) é uma decisão que cada vez é mais complexa. Visto que, gera dilemas que não estão relacionados apenas com características pessoais, mas principalmente ao contexto histórico e ao ambiente sociocultural em que o jovem vive.

Diversas são as razões que influenciam a escolha da profissão, entre elas Mira, Withers e Guidini (2010) destacam: a satisfação pessoal; acessibilidade financeira do curso; função política idealizada; possibilidade de destaque social; influência familiar; salário e perspectivas do mercado. No caso da profissão docente, de acordo a pesquisa da Fundação Victor Civita e da Fundação Carlos Chagas, não é considerada pelos estudantes de Ensino Médio uma opção atraente, apenas 2\% desejam cursar Pedagogia ou Licenciatura (RATIER, SALLA, 2010). Por motivos como: “o trabalho é mal remunerado e o docente é confrontado pelos alunos, esquecido pelo governo e desvalorizado pela sociedade" (Ibid., 2010, p. 7).

Considerando o exposto acima, questionamos aos PFI sobre as razões que influenciaram na escolha da profissão docente. Por ser uma questão aberta, suas respostas poderiam incluir mais de uma razão, as quais foram utilizadas para construir as categorias emergentes deste tópico: gosto de ensinar e influência (Figura 2).

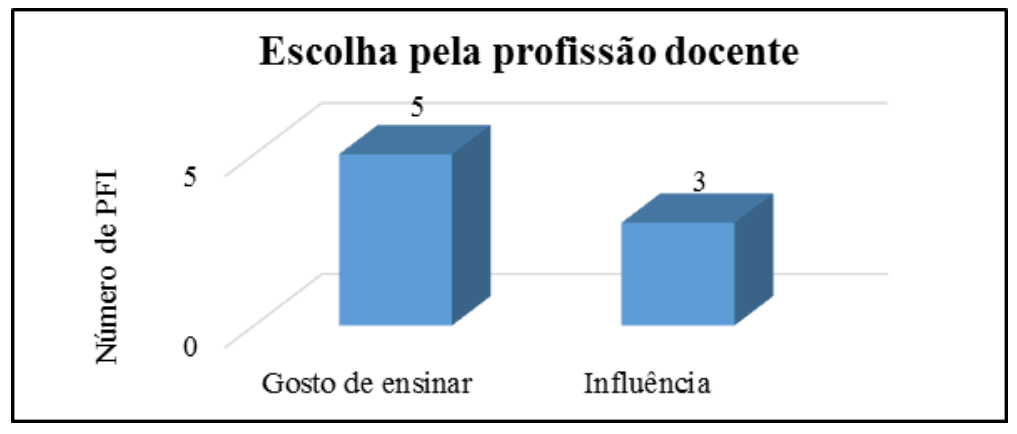

Figura 2 - Razões da escolha pela profissão docente.

É possível observar que o gosto em ensinar, foi a principal razão dos PFI para escolha da profissão docente. Afinidade identificada pelos PFI a partir da brincadeira de ser professor quando criança, como é destacada em suas respostas: 
PFI2: "Quando criança brincava de ser professor e meus pais serem meus alunos, adorava essa brincadeira em que eu fazia questões de matemática e entregava para meus pais responderem".

PFI6: "Para mim a escolha de ser docente não foi de primeira, tive muitas dúvidas, para tomar a decisão recordei-me de como eu adorava brincar de ser professora para os meus alunos imaginários, passava tarefas para um familiar fazer como temas de casa".

Também, a escolha por ser docente foi uma decisão influenciada por familiares e professores da escola, como é citado pelos PFI.

PFI3: "Influência da família e de ótimos professores que tive na escola".

PFI4: "Desde o Ensino Fundamental tinha a ideia de ser professor, mas no Ensino Médio tive a certeza da escolha. Tive grande influência da minha professora de Química, pois gostava muito da maneira como ela ensinava".

2. Predileção pela docência em ciências: A fim de identificar a preferência dos PFI pela docência em ciências, foram questionados sobre o porquê de sua escolha. Com as respostas fornecidas pelos PFI, emergiram as categorias que revelam que sua predileção foi: o gosto pela disciplina (1 PFI), por explicar os fenômenos naturais (4 PFI) e por ser uma disciplina com base empírica (1 PFI). Conforme podemos observar nas respostas dos PFI.

PFI2: "Pois as ciências são mais aplicadas, fugindo da mera descrição de conteúdos teóricos".

PFI4: "Porque a Ciência sempre me chamou muito atenção, desde o Ensino Fundamental, e no Ensino Médio meu interesse era voltado para as disciplinas de Química e Biologia”.

PFI5: "Porque me chama atenção estudar os fenômenos que explicam a natureza".

Estas respostas concordam com os resultados de outras pesquisas, das quais destacamos a realizada por Cardoso e Colinvaux (1999), que menciona que o interesse pelas ciências está relacionado com:

- O gosto pela disciplina, que está condicionado ao assunto estudado, se é acompanhado de aulas práticas, a sua facilidade de assimilação e a afinidade com o professor. 
- A aplicação dos conhecimentos importantes em suas vidas ou futura profissão.

- A atração demonstrada em conhecer e entender as substâncias, os fenômenos da natureza e do cotidiano.

3. Objetivo da educação: Considerando que a aprendizagem significativa é um objetivo a ser alcançado e proposto desde 1998 pelos PCNEM, questionou-se os PFI sobre suas considerações em relação aos objetivos da educação, com o intuito de determinar se os PFI identificam a aprendizagem significativa como um deles. As respostas obtidas permitiram a construção das categorias emergentes: Formação de cidadãos, Contextualização dos conteúdos e Transmissão dos conteúdos (Figura 3).

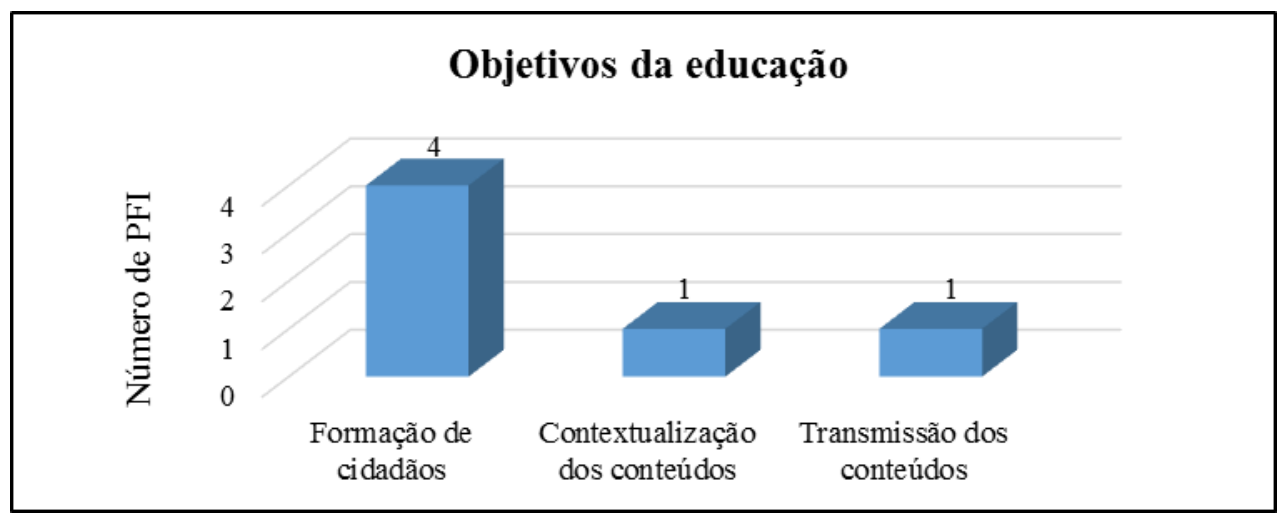

Figura 31 - Objetivos da educação identificados pelos PFI.

Em relação aos objetivos da educação, percebe-se que 4 PFI destacaram a importância da formação voltada para a cidadania, na qual segundo o PFI5 deve-se "formar indivíduos críticos e ativos na sociedade", adquirindo, de acordo com o PFI3 "habilidades variadas para participar na sociedade". Esses aspectos corroboram com Santos e Schnetzler (1996), que consideram que é importante adquirir conhecimentos mínimos de ciências como a Química, para participar com maior fundamentação na sociedade atual, para compreender, analisar e tomar decisões relacionadas aos problemas sociais, que podem ser evidenciados de acordo com o contexto do estudante.

Além disso, o PFI4 destaca como objetivo da educação a contextualização dos conteúdos com aspectos relacionados ao contexto social, como é evidenciado em sua resposta ao mencionar que o objetivo é "relacionar para os alunos os conteúdos com sua vida". Segundo Silva e Núñez (2007), apresentar situações que tornem os conteúdos 
escolares, como as formulações abstratas da Química (modelos teóricos) em conteúdos significativos e funcionais para o aprendiz.

Por último, para esta questão só 1 PFI considera que o objetivo da educação é a transferência do conhecimento, tendo uma visão mais conteudista do processo de ensino-aprendizagem. No entanto, com a análise deste metatexto constata-se que os PFI não identificam a aprendizagem significativa como um objetivo da educação.

4. Modelo epistemológico: As concepções epistemológicas de acordo com Tardif (2002) "expressam um paradigma de pensamento educacional sobre a compreensão que se tem do conhecimento e que potencializa nas práticas pedagógicas docentes" (apud PASQUETTI e BRUN, 2009, p 15). Estas concepções influenciam no desenvolvimento do modelo pedagógico, processo de ensino-aprendizagem e o papel que o docente e o estudante desempenham em sala de aula.

Nesta pesquisa, identificou-se o modelo pedagógico construído pelos PFI, a partir das concepções epistemológicas sobre a aprendizagem, o papel do professor no processo de ensino - aprendizagem e o papel do estudante nesse processo. Classificando-se os PFI dentro das categorias a priori: empirista (E) ou construtivista (C).

Podemos observar na Figura 4, que a concepção epistemológica dos PFI sobre a aprendizagem tem uma tendência construtivista (só um PFI evidencia um modelo epistemológico empirista). Entretanto, a respeito das considerações sobre o papel do professor e do estudante no processo de ensino-aprendizagem a tendência muda para um modelo epistemológico empirista. Esta classificação se justifica nas respostas fornecidas pelos PFI, como é descrito a seguir. 


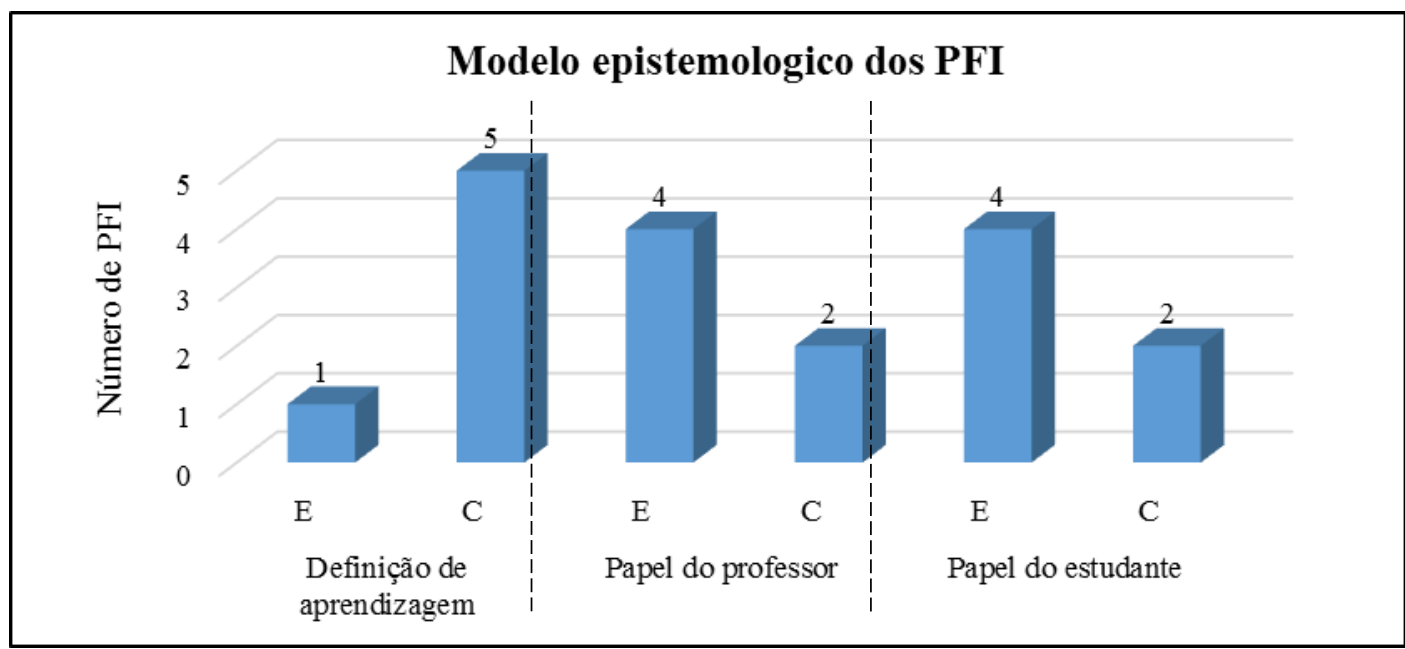

Figura 4 - Modelo epistemológico dos PFI.

O modelo epistemológico empirista é considerado um modelo conteudista, no qual a "fonte do conhecimento humano está na experiência adquirida em virtude do meio físico com mediação dos sentidos" (FACIN, 2015, p. 102). Constatou-se em algumas concepções que a aprendizagem só acontece se o professor ensina, centrandose o processo de ensino-aprendizagem no professor, que tem como papel na sala de aula, segundo os relatos: PFI3: “A aprendizagem é que os estudantes aprendam um determinado conteúdo" e PFI2 "O papel do professor é transmitir os conhecimentos técnicos e práticos aos alunos".

Por outro lado, o papel do aluno no modelo empirista é um papel passivo, de acordo com o PFI1: "receptor das informações", pois considera uma "tábula rasa", "folha de papel em branco" ou uma "esponja" que "absorve os conhecimentos transmitidos pelo professor" como foi mencionado pelos PFI2 e 3.

A Adoção deste modelo epistemológico por alguns PFI pode ter sido influência de suas vivências como estudantes na escola. Estas vivências constroem uma "pedagogia do senso comum", levando os PFI a reproduzirem metodologias tradicionais no processo de ensino, como é destacado pelos PFI1,2 e PFI3 “aulas como os professores ensinaram na escola", o que desfavorece a aprendizagem significativa em sala de aula.

Por outro lado, o modelo construtivista segundo a teoria da aprendizagem significativa de Ausubel, vê a aprendizagem como um "processo no qual o aluno 
entende um fenômeno ou um conceito e consegue aplicá-lo ou dar-lhe significado na resolução de um problema" (PFI5), o qual precisa segundo o PFI4 que "o aluno e o educador conciliem o resultado do estudo", por meio da interação entre o professor e o estudante. O papel do professor na perspectiva construtivista é um orientador que exerce a função conforme PFI5 de "facilitar e intermediar o modo como é ensinado algum conceito", para que o estudante, segundo o mesmo PFI, deve "ter disposição para aprender e relacionar com o que ele vive e ser ativo no processo", para com isso, como menciona o PFI6, "ir construindo seu conhecimento".

Destaca-se que embora os PFI tenham a mesma formação pedagógica e didática oferecida pela universidade, não possuem o mesmo modelo epistemológico, dado que é uma construção das diferentes experiências de cada PFI, desde a etapa como estudantes na escola. Percebeu-se, que os PFI não possuem um modelo epistemologico definido que oriente seu fazer docente em sala de aula.

5. Critérios para o planejamento da aula: Dentro deste tópico, o objetivo foi identificar se os PFI conheciam os critérios para o planejamento de uma aula e principalmente se consideravam as ideias prévias dos estudantes, pois como menciona Ausubel (1978), as ideias prévias são um fator isolado importante que influencia na aprendizagem, o autor recomenda averiguar e ensinar de acordo com elas.

A partir dos resultados constatou-se que os PFI reconheciam critérios básicos para a elaboração de um planejamento da aula como: objetivos, conteúdos, tempo e o contexto. Mas, não reconheciam a importância dos conhecimentos prévios para o planejamento da aula, com exceção do PFI6 que considera como critério "os conhecimentos prévios dos estudantes por que podem ser aproveitados". É importante mencionar que por ser uma pergunta aberta os PFI poderiam fornecer mais de uma resposta, as quais foram classificadas como categorias emergentes (Figura 5). 


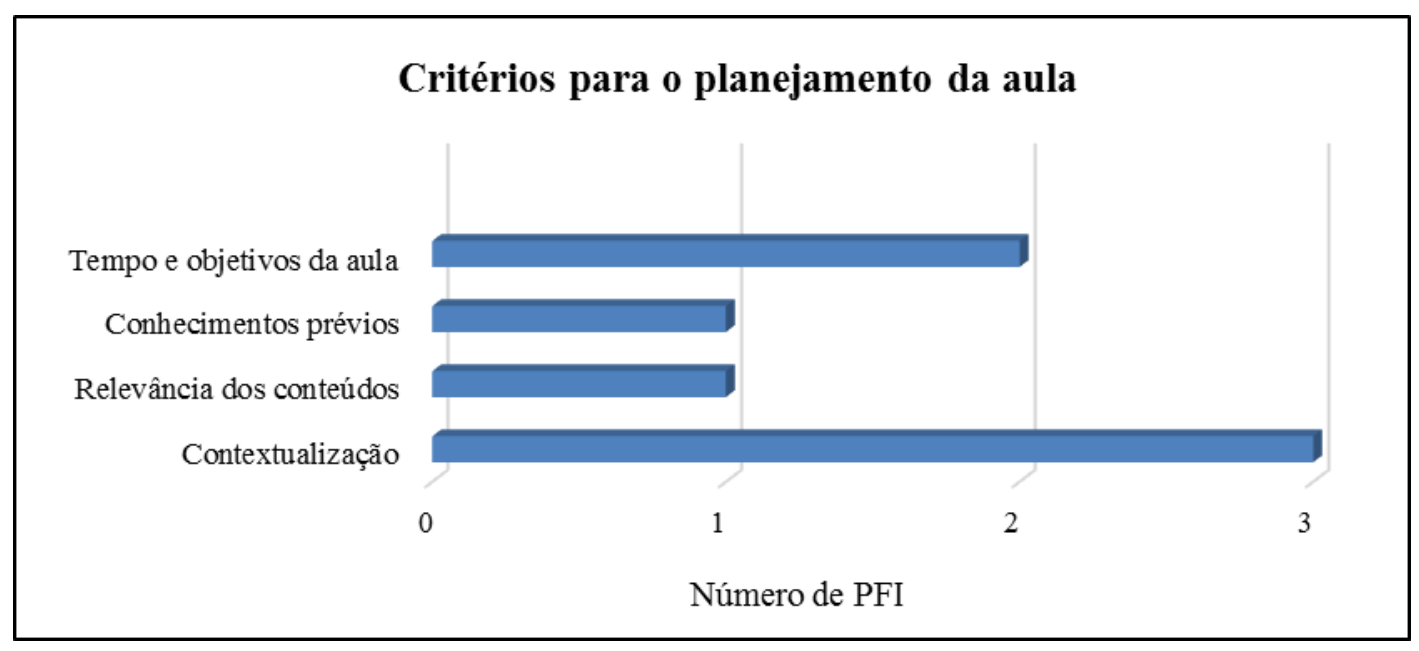

Figura 5 - Critérios para o planejamento da aula.

6. Atividades didáticas: As atividades didáticas são definidas pelo glossário CEALE (Centro de Alfabetização, Leitura e Escrita) da Universidade Federal de Minas Gerais como "mediadores da relação entre os alunos e um objeto de conhecimento ou entre as relações sociais inerentes ao contexto pedagógico". Sendo uma ferramenta para o professor, que auxilia o processo de ensino-aprendizagem e que permite a interação entre os alunos com o objeto de conhecimento. Na perspectiva da aprendizagem significativa as atividades didáticas podem ser materiais potencialmente significativos, é por isso que os PFI foram questionados sobre quais atividades de ensino utilizam na sala de aula.

Os resultados foram esquematizados e categorizados de forma emergente em: jogos didáticos, atividades experimentais, contextualização e questionários, conforme ilustrado na Figura 6. Destaca-se que a escolha de jogos didáticos por parte dos PFI, pode ter sido influenciada pelo grupo PIBID, já que as atividades elaboradas e aplicadas pelo grupo fazem uso de jogos didáticos.

Além disso, é possível observar que só um PFI considera como metodologia de ensino o questionário, embora não seja uma resposta errada, uma vez que dependendo do tipo de questionário, tempo e objetivo de sua aplicação, pode contribuir para o processo de ensino-aprendizagem. Entretanto, os questionários são mais utilizados como objeto de avaliação para detectar de que maneira está sendo construído o conhecimento ou para reforçar os conteúdos (NUNES, 2014). 


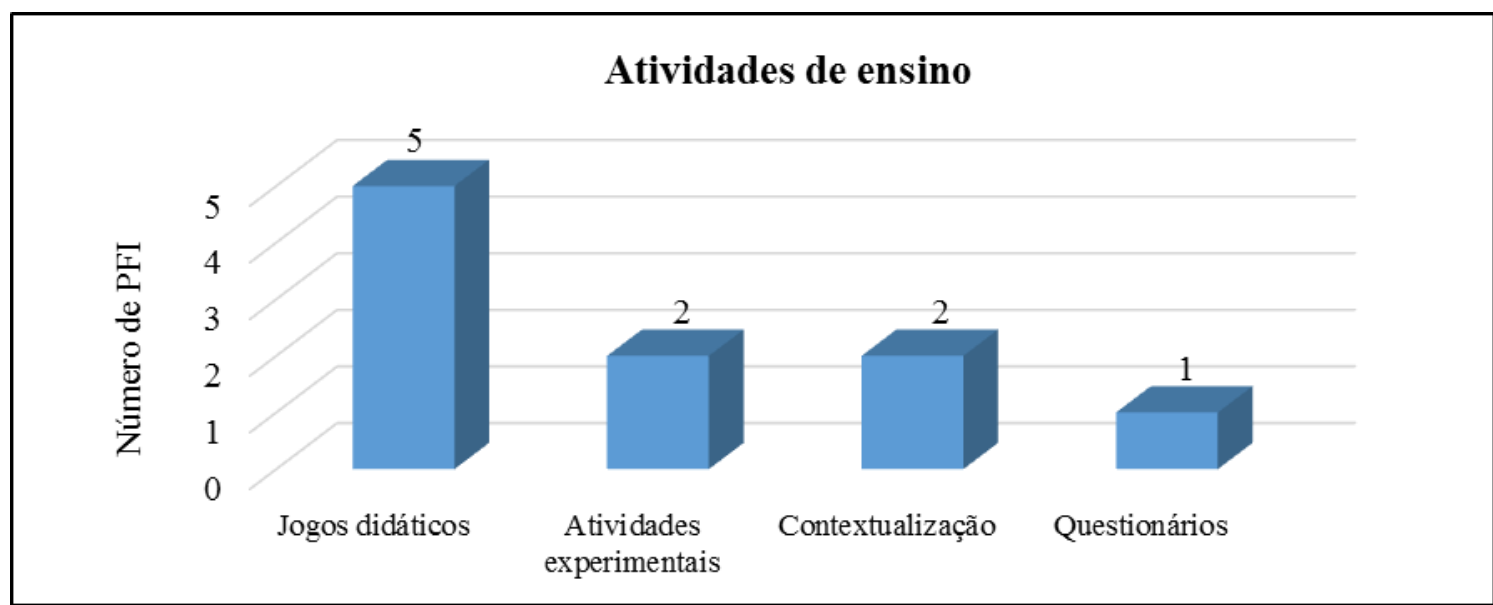

Figura 6 - Atividades de ensino citadas pelos PFI.

7. Critérios para escolher as atividades de sala de aula: Os materiais potencialmente significativos de acordo com Moreira, Caballero e Rodríguez (1997) devem ser coerentes e relacionáveis de maneira não-arbitrária e substantiva à estrutura cognitiva do estudante, além de serem coerentes com os conteúdos a serem ensinados, sendo estes os critérios para sua escolha. Para determinar quais são os critérios selecionados pelos PFI para a escolha das atividades didáticas, eles foram questionados sobre estes criterios, as respostas obtidas estão apresentadas na Figura 7, as quais para a análise são consideradas como categorias emergentes.

Percebe-se na Figura 7 que os PFI não manifestaram importância aos conhecimentos prévios e ao nível cognitivo do estudante para a escolha e elaboração das metodologias de ensino, o que faz com que as atividades só sejam coerentes com os conteúdos e não com a estrutura cognitiva do estudante.

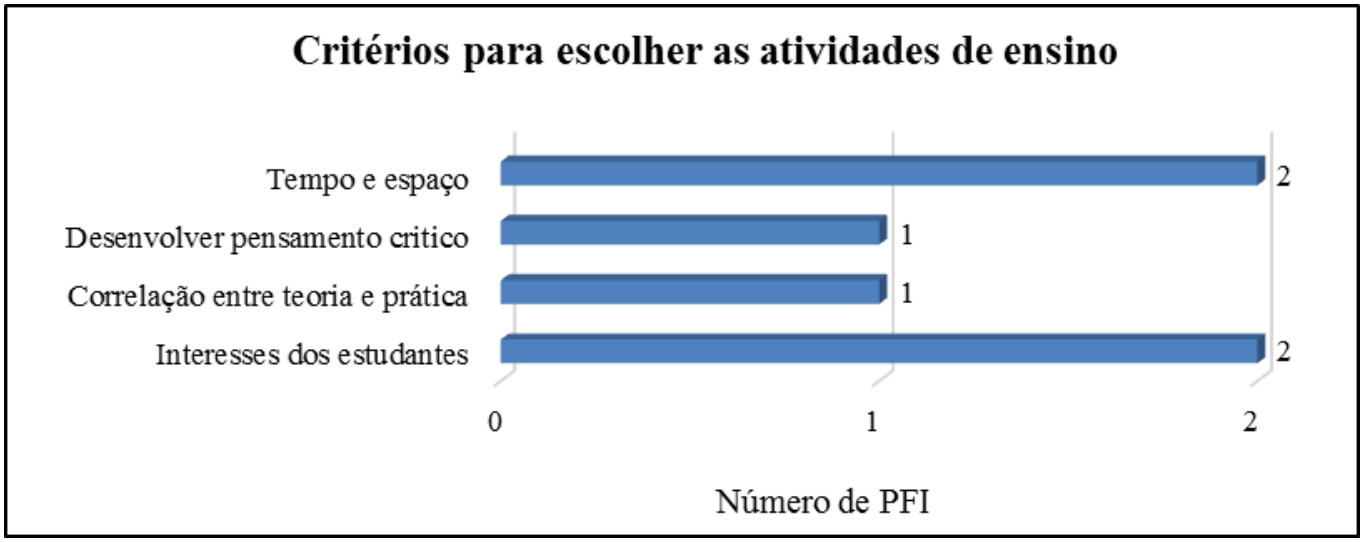

Figura 7 - Critérios dos PFI para escolher as atividades de ensino. 


\section{CONSIDERAÇÕES FINAIS}

A aprendizagem significativa é uma proposta de aproximadamente 50 décadas, mudando no decorrer do tempo de uma visão clássica até uma visão crítica. No entanto, ainda mantêm como objetivo e fundamento a construção de um novo conhecimento a partir da interação não-arbitrária e não-literal com os conhecimentos prévios dos estudantes. Não obstante, nesta pesquisa conclui-se que embora a aprendizagem significativa seja uma teoria que influencia nas diretrizes educacionais como nos PCNEM, os professores em formação inicial ainda não possuem o conhecimento pedagógico e didático para alcançá-la em sala de aula, sendo uma das razões pela qual a formação inicial de professores é fortemente criticada, por considerar que não atende suficientemente as necessidades da sociedade brasileira.

Dentro desta perspectiva os resultados obtidos nesta pesquisa fundamenta-se ao identificar que os professores em formação não consideram a aprendizagem significativa um objetivo a ser alcançado dentro da educação. Além disso, considera-se que os professores em formação inicial não conhecem as condições para favorecer a aprendizagem significativa em sala de aula, como a identificação e utilização das ideias prévias para o planejamento de suas aulas e elaboração de atividades didáticas (materiais potencialmente significativos) que sejam coerentes com as estruturas cognitivas dos estudantes. $\mathrm{O}$ não conhecimento das condições para alcançar a aprendizagem significativa na sala de aula, pode ser consequência do modelo epistemológico adaptado pelos professores em formação inicial, observando-se que o modelo epistemológico adotado, embora ainda não definido por alguns professores em formação inicial é empírico, acreditando ainda na transmissão do conhecimento. Consequência da falta de fundamentação pedagógica e didática por parte dos professores em formação inicial e de sua experiência como estudantes na escola, onde possivelmente foram ensinados de forma tradicional.

Portanto, recomenda-se incentivar fortemente os professores em formação inicial a participarem de pesquisas e de elaboração de metodologias didáticas que sirvam como estratégia de ensino onde o estudante seja participante e construa seu conhecimento de forma ativa, com o objetivo de fortalecer suas concepções pedagógicas e didáticas de 
forma teórica e prática. Além de favorecer a aprendizagem significativa na sala de aula e conseguir mudanças nos processos educativos.

\section{REFERÊNCIAS}

AUSUBEL, D. P. Psicología educativa: un punto de vista cognoscitivo. 1. Ed. México - DF: Trillas S. A. 1978.

BRASIL. Ciências da Natureza, Matemática e suas Tecnologias. Parâmetros Curriculares Nacionais para o Ensino Médio. Brasília: MEC/SEF, 1998.

Ciências da Natureza, Matemática e suas Tecnologias. Parâmetros

Curriculares Nacionais - Ensino Médio: Orientações Educacionais Complementares aos Parâmetros Curriculares Educacionais. Brasília: MEC/SEMTEC, 2002.

Ministério da Educação. Secretaria de Educação Básica. Orientações Curriculares para o Ensino Médio. Ciências da Natureza, Matemática e suas Tecnologias. Brasília, 2006.

CARDOSO, S. P.; COLINVAUX, D. Explorando a motivação para estudar Química. Revista Química Nova, v. 23, n. 2, p. 401 - 404, 1999.

CASTILlO, A.; RAMIREZ, M.; GONZALEZ, M. El Aprendizaje Significativo de la Quimica: Condiciones para lograrlo. Revista Omnia, Venezuela, v. 19, n.2, p. 11-24, 2013.

CONCEITO. de. Conceito de Formação. 2011. Disponível em: <http://conceito.de/formacao> Acesso em: 19 maio. 2016.

FACIN, C. E. Reflexões sobre os modelos epistemológicos e pedagógicos de um grupo de educadores. Revista Unoesc \& Ciência, Joaçaba, v. 6, n. 1, p. 99 - 110, 2015.

GATTI, B. A.; TARTUCE, G. L. B. P.; NUNES, M. M. R.; ALMEIDA, P. C. A. de. A atratividade de carreira docente no Brasil. Estudos e pesquisas educacionais: Fundação Victor Civita. São Paulo - SP, 2009.

GIL, P. D. Tres Paradigmas Básicos en la Enseñanza de las Ciencias. Enseñanza de las ciencias. Revista Enseñanza de las Ciencias, Barcelona, v. 1, n.1, p. 26 - 33, 1983. 
¿Qué hemos de saber y saber hacer los profesores de ciencias? Revista enseñanza de las ciencias, v. 9, n. 1, pág. 69 -77. 1991.

GLOSSÁRIO DO CENTRO DE ALFABETIZAÇÃO, LEITURA E ESCRITA (CEALE). Atividade didática. Disponível em: < http://ceale.fae.ufmg.br/app/webroot/glossarioceale/verbetes/atividade-didatica> Acesso em: 17 maio. 2016.

HYPOLITTO, D. Formação docente em tempos de mudança. Revista Integração, São Paulo, v. 14, n. 56, p. $91-95,2009$.

NUNES, M. I. de M. Mídia na educação. 2014. 26 f. Monografia (Especialização em Fundamentos da Educação: Práticas Pedagógicas interdisciplinares) -Universidade Estadual da Paraíba, Monteiro - PB. 2014.

MENDEZ, Z. Aprendizaje y Cognición. 1. ed. Costa Rica: Universidad Estatal a Distancia. 1993.

MIRA, M. M.; WITHERS, W. S.; GUIDINI, F. Ser professor? Não, obrigado! Reflexões sobre a escolha profissional dos estudantes do ensino médio. In: VIII Encontro de Pesquisa em Educação da Região Sul - Anped Sul, 2010, Londrina. Anais do VIII Encontro de Pesquisa em Educação da Região Sul - Anped Sul, 2010.

MORAES, R.; GALIAZZI, M. do C. Análise textual discursiva: processo reconstrutivo de múltiplas faces. Revista Ciência \& Educação, v. 12, n. 1, p. 117-128, 2006.

MOREIRA, M. A. Pesquisa em ensino: aspectos metodológicos. Universidad de Burgos departamento de didácticas especificas. España. 2003.

Aprendizagem Significativa: Da Visão Clássica à Visão Crítica. In: I Encontro Nacional de Aprendizagem Significativa, 1., 2005, Campo Grande/MS. Anais... I Encontro Nacional de Aprendizagem Significativa, 2005.

A Teoria da Aprendizagem Significativa. 1. ed. Porto Alegre, 2009.

Teorias de Aprendizagem. 2. ed. São Paulo: Pedagógica e Universitária LTDA, 2011. 
MOREIRA, M. A.; CABAllerO, M. C.; RODRÍGUEZ, M. L. Aprendizaje significativo: un concepto subyacente. Acta del Encuentro Internacional sobre el Aprendizaje Significativo. Burgos, España, p. 19 - 44, 1997.

MOREIRA, M. A.; SALZANO, Et Al. Aprendizagem Significativa, Condições para ocorrências, e lacunas que levam a comprometimentos. 1. ed. São Paulo: Psico pedagógica LTDA, 2008.

OLIVEIRA, M. A. R.; et al. Formação Inicial de Professores da Educação Básica no Brasil: Trajetória e Perspectivas. Revista Diálogo Educacional, Curitiba, v.12, n. 37, p. $997-1026,2012$.

PASQUETTI, R.; BRUN, M. D. As concepções epistemológicas e os modelos pedagógicos que orientam as práticas dos docentes dos docentes de PROEJA do IFRS - Campus Bento Gonçalves. 2009. 37p. Especialização - Universidade Federal do Rio Grande do Sul. Porto Alegre, BR-RS, 2009.

RATIER, R.; SAlLA, F. Escolha de Poucos. Revista Nova Escola. São Paulo: Ed. Abril, p. 4 - 17. 2010.

RODRIGUEZ, P. L.; et al. La Teoría del Aprendizaje Significativo en la Perspectiva de la Psicología Cognitiva. 1. ed. Barcelona: Octaedro, 2010.

RODRIGUEZ, P. M. L.; CABAllerO, S. C.; MOREIRA, M. A. Aprendizaje Significativo y Formación del Profesorado. Revista Aprendizagem Significativa em Revista, Porto Alegre, v.1, n.1, p. 58 - 83, 2011.

SANTOS, W. L. P.; SCHNETZLER, R. P. Função social: o que significa ensino de química para formar o cidadão? Revista Química Nova na Escola, n. 4, p. 28 - 34, 1996.

SERRA, H. Formação de professores e formação para o ensino de ciências. Revista Educação e Fronteiras On-Line, v. 2, n. 6, p. 24 - 36, 2012.

SILVA, L. M. G.; NÚÑEZ, B. I. O contexto escolar, o cotidiano e outros contextos. Instrumentação para o Ensino de Quimica II, 1. ed. Natal, 2007. 